\title{
A Dinâmica da Relação Entre Poder e Direito no Tridimensionalismo Jurídico de Miguel Reale
}

\section{SÉRGIO ANTÔNIO FERREIRA VICTOR}

Doutor em Direito, Coordenador Adjunto do Programa de Mestrado em Direito Constitucional da EDB/IDP, Assessor de Ministro do STF.

Submissão: 29.06 .2015

Decisão Editorial: 02.07.2014

Comunicação ao autor: 02.07.2014

RESUMO: 0 presente artigo procura desvendar o pensamento de Miguel Reale em parte essencial ao direito público, concernente às suas concepções de soberania, poder e direito. Sob a óptica de Reale, poder e direito relacionam-se em diversos níveis sociais e do Estado, formando ordens jurídicas parciais, as quais exercem pressão sobre as instituições estatais, no intuito de se tornarem parte da ordem total (estatal), a partir de uma decisão soberana. Assim, em Reale, distintamente do que afirma Kelsen, a decisão é parte do fenômeno formador do ordenamento e Direito e Estado não se confundem. A atualidade do pensamento de Reale está em que suas bases provêm tanto da dinâmica da sociedade considerada em suas diversas manifestações como na essência do poder do Estado, sem descurar das liberdades dos cidadãos, que, por consentimento, conferem legitimidade ao ordenamento jurídico.

PALAVRAS-CHAVE: Miguel Reale; tridimensionalismo jurídico; soberania; poder; direito.

ABSTRACT: This paper examines the conceptions of sovereignty, power and law within the framework of Miguel Reale's public law theory. From Reale's point of view, the many interactions of power and law both within the civil society and the State form partial legal systems aspiring to become part of the whole system of State Law through a sovereign decision. Reale departs from Kelsen's theory in that he does not equate the Law and the State and recognizes decision as a fundamental part of the formation of legal order. Thus Reale's theory remains relevant as an attempt to establish both the dynamics of society and the power of the State as the basis for the formation of Law, and the protection of the rights of the citizens and their participation in the public decision-making processes as the basis for the legitimate exercise of sovereignty.

KEYWORDS: Miguel Reale; three-dimensional theory of law; sovereignty; power; law.

SUMÁRIO: Introdução - Soberania, poder e direito em evolução; 1 Soberania, poder e direito em Reale; 2 Pluralismo jurídico, dinâmica da correlação poder e direito e gradação da positividade; 3 A institucionalização do Poder. Despersonalização e transpersonalização - A redução do quantum despótico; Conclusão; Referências.

\section{INTRODUÇÃO - SOBERANIA, PODER E DIREITO EM EVOLUÇÃO}

Pode-se dizer que a ideia separação de poderes tem como um de seus principais inspiradores o teórico da concentração do poder, Jean Bodin (1530- 
1596). O notável jurista e pensador político, estudando a sociedade feudal de seu tempo, que se baseava nas relações de dependência pessoal entre senhores e vassalos, verificou a necessidade de se alterar o centro de legitimidade da organização política no sentido de uma objetivação do poder, revelando-se como instrumento adequado ao seu intuito o desenvolvimento do conceito de soberania ${ }^{1}$.

Ideia concebida tendo em vista a necessidade de unificação do poder, a soberania transformou-se, de fato, em instrumento utilizado pelos estadistas europeus da época para empreenderem a almejada unificação. Impactou profundamente o pensamento das elites francesas e inglesas, sobretudo no que concerne à construção jurídica do conceito de Estado-Nação².

Para Bodin, a soberania caracteriza-se por ser perpétua e absoluta, além de concentrada pelo príncipe detentor do poder de dar e suprimir a lei ${ }^{3}$. Assim, sustenta que o soberano detém o monopólio legislativo e que a ele cabe decretar a guerra e firmar a paz, instituir funcionários, nomear magistrados e tributar. Todavia, apesar de absoluto, o poder não é ilimitado. Bodin, atento à lição medieval, tinha como finalidade da lei a justiça e afirmava ser uma incongruência dizer que o rei pudesse fazer algo que não fosse honesto, visto que seu poder deve ser medido com a vara da justiça ${ }^{4}$, observando sempre que a lei deveria conformar-se ao Direito, à lei natural ou divina ${ }^{5}$.

Bodin teria inspirado os teóricos políticos posteriores na medida em que criou uma distinção fundamental e caríssima à evolução da doutrina da divisão do poder: a soberania em sua essência (la souveraineté) e a soberania em seu exercício (le gouvernement). Cezar Saldanha afirma que, somente a partir dessa distinção, o direito público passa a admitir a compossibilidade jurídica entre a unidade e indivisibilidade de um poder soberano nacional do Estado ao lado da pluralidade e divisibilidade do exercício das funções políticas contidas na soberania. Funções consequentemente partilháveis entre órgãos separados institucionalmente e que viriam a ser chamados de poderes políticos ${ }^{6}$.

Dessa forma, o monarca teria auxílio para governar, mas a Constituição não seria mista, uma vez que, individualizado de forma inequívoca, o soberano deteria o poder último, que não resultaria de uma composição de interesses de

1 GALA, Pedro Bravo. Estúdio preliminar. In: BODIN, Jean. Los seis libros de la República. 4. ed. Madrid: Editorial Tecnos, 2006. p. LIV-LV.

2 SOUZA JÚNIOR, Cezar Saldanha. O tribunal constitucional como poder: uma nova teoria da divisão dos poderes. São Paulo: Memória Jurídica, 2002. p. 36.

3 BODIN, Jean. Los seis libros de la República. 4. ed. Madrid: Editorial Tecnos, 2006. p. 47-51.

4 BODIN, Jean. Op. cit., p. 63-64.

5 FERREIRA FILHO, Manoel Gonçalves. Do processo legislativo. 5. ed. rev., ampl. e atual. São Paulo: Saraiva, 2002. p. 38

6 SOUZA JÚNIOR, Cezar Saldanha. Op. cit., p. 38-9. 
segmentos da sociedade ${ }^{7}$. Assim, a soberania (essência) restaria subtraída das forças políticas ordinárias, possibilitando que o rei zelasse pela perenidade do Estado $^{8}$.

Anos após serem lançadas na França as ideias de Bodin, a monarquia é restaurada na Inglaterra, porém, ao fim do século XVII, o rei tem seu poderes limitados em função da Revolução Gloriosa, que deu azo ao advento do Bill of Rights. Inicia-se a construção de uma forma de governo moderado que teve em John Locke (1632-1704) atento observador. Locke pensava a sociedade política como resultado do consentimento dos seus participantes imaginados em estado de natureza, caracterizado este pela perfeita liberdade e perfeita igualdade, porém faltariam três importantes elementos aos homens nesse estado: leis que diferenciassem o meu do seu, juízes imparciais que decidissem eventuais litígios e uma força pública que restabelecesse os direitos quando considerados violados. Para alcançarem essas três coisas é que os homens aceitariam viver em sociedade, cedendo parcelas de seus direitos naturais (contrato social) ${ }^{9}$.

Com isso, tendo em vista a divisão do poder e o papel central desempenhado pelas liberdades civis a partir da adoção do Bill of Rights, caminhou-se para uma supremacia do Parlamento ${ }^{10}$ que passou a deter o monopólio legislativo, bem como a possibilidade de impedir que, sem sua autorização, o monarca impusesse tributos, convocasse e mantivesse o exército, tudo isso tendo como pano de fundo a proteção ao direito de propriedade ${ }^{11}$.

O modelo inglês ganha notoriedade como sendo o ideal para a configuração política da sociedade; então, no século XVIII, recebe um notório aprimoramento com a obra de Montesquieu (1689-1755). Estudando a Constituição Inglesa, mas somando-Ihe novos contornos e escrevendo de forma abstrata o suficiente para que sua descrição de um modelo pudesse se tornar a proposta de uma forma ainda mais refinada de organização política, Montesquieu desenha a célebre tripartição dos poderes-funções em cada Estado: Legislativo, Executivo das coisas que dependem do direito das gentes (fazer a guerra e a paz, cuidar da segurança, prevenção de invasões) e o Executivo das coisas que dependem do direito civil (poder de julgar: punir criminosos e decidir querelas entre os particulares) ${ }^{12}$.

7 FIORAVANTI, Maurizio. Constitución: da la antiguedad a nuestros dias. Madrid: Trotta, 2001. p. 75.

8 BRANCO, Paulo Gustavo Gonet. Vale quanto pode: a força jurídica da Constituição como pressuposto elementar do constitucionalismo atual. Revista de Direito Público, Brasília: Síntese/IDP, n. 14, out./dez. 2006.

9 FERREIRA FILHO, Manoel Gonçalves. Op. cit., p. 41-2.

10 BRANCO, Paulo Gustavo Gonet. Op. cit.

11 LOCKE, John. Dois Tratados sobre o governo: Livro II: Segundo Tratado. 1. ed. 2. tir. São Paulo: Martins Fontes, 2001. p. 510-13.

12 LEAL, Roger Stiefelmann. O efeito vinculante na jurisdição constitucional. São Paulo: Saraiva, 2006. p. 6-7. 
Nesse esteio, a liberdade foi o valor jurídico máximo que serviu como motor, como razão última de sua teoria da separação dos poderes ${ }^{13}$. Consequência disso foi o reforço da posição soberana do órgão incumbido de elaborar as leis (já que somente estas poderiam restringir a liberdade) e a criação da faculdade de impedir que os poderes têm uns em relação aos outros, justamente no sentido de dificultar o acordo e, portanto, a produção de leis. Cumpre ressaltar que, a partir dessas faculdades de impedimento que possui cada poder com relação aos demais, criou-se a doutrina de limitação do poder pelo poder que ficou conhecida como checks and balances ${ }^{14}$.

O que interessa nesse momento é verificar que a tradição referida e que tem em Montesquieu um expoente pensa o poder como uma substância. Por isso discutiu-se tanto sobre o monopólio ou a divisão do poder, sobre quem detém o poder e sobre a probabilidade de aquele que detém o poder vir a dele abusar. Esse pensamento dominou o surgimento do que se convencionou chamar de constitucionalismo moderno, norteado pela intenção de limitar o poder por meio de sua divisão em funções, bem como pelo respeito às declarações de direitos que surgiram.

A crítica mais veemente que surgiu a essa corrente de pensamento foi trazida pela escola Marxista. Marx contesta as ideias liberais afirmando que o verdadeiro poder está nas mãos daqueles que têm o domínio das relações econômicas. O poder econômico submeteria os indivíduos e os direitos declarados pelas Cartas liberais teriam valor apenas formal, uma vez que não podem se fazer valer face ao poderio econômico de uma minoria. Para a tradição marxista, portanto, o poder, ainda que se manifeste nas relações econômicas, pode ser considerado como uma substância: detém o poder aquele que domina as relações econômicas, isto é, o poder resume-se ao poder econômico ${ }^{15}$.

Weber procurou evoluir relativamente à tradição marxista. Para ele, o poder não é uma substância, mas dá-se em uma relação. Aliás, o poder manifesta-se em quaisquer espécies de relações. Aron, referindo-se às ideias de Weber, afirmou que

o poder é definido simplesmente como a probabilidade de um ator impor sua vontade a outro, mesmo contra a resistência deste. Situa-se, portanto, dentro de uma relação social, e indica a situação de desigualdade que faz com que um dos atores possa impor sua vontade ao outro. ${ }^{16}$

13 LOEWENSTEIN, Karl. Teoría de la Constitución. Barcelona: Ediciones Ariel, 1979. p. 55.

14 MONTESQUIEU. O espírito das leis. 3. ed. São Paulo: Martins Fontes, 2005. p. 170-173.

15 MARX, Karl. A questão judaica. Disponível em: <http://www.lusosofia.net/textos/marx_questao_judaica.pdf> . Acesso em: 26 jun. 2015.

16 ARON, Raymond. As etapas do pensamento sociológico. São Paulo: Martins Fontes, 2002. p. 806. 
Em sentido semelhante, Foucault aduziu que o sistema do direito é completamente centrado no rei, na eliminação de sua dominação, o que coincide com o pensamento referido acima, cujo expoente foi Montesquieu, no que tange à limitação do poder. Além disso, ao afirmar que a soberania é o problema central do direito nas sociedades ocidentais, em verdade diz que a técnica do direito exerceu a função de dissolver o fato da dominação dentro do poder para fazer surgir direitos da soberania e sua obrigação legal de obediência ${ }^{17}$. O importante nesse itinerário, em especial nos contornos propostos por Weber e Foucault, é o fato de o poder surgir nas relações. São múltiplas as formas de dominação que podem se exercer nas sociedades, de forma que o poder ou a dominação não é exercida apenas pelo rei, mas pelos próprios súditos em suas relações recíprocas: "Não a soberania em seu edifício único, mas as múltiplas sujeições que existem e funcionam no interior do corpo social"18. Finalizando com Tercio Ferraz: "O poder é, na sociedade, uma qualidade imanente aos indivíduos" ${ }^{\prime 19}$.

Traçar brevemente esse itinerário pode ajudar a entender o contexto de Reale e permitirá a verificação de semelhanças entre algumas das ideias esposadas e o pensamento realeano. A ideia de poder que se manifesta nas relações, em diversos níveis e espécies de relações, parece permear as obras de Reale e iluminar algumas de suas principais noções que aqui serão analisadas: o pluralismo jurídico e a teoria tridimensional do direito.

\section{SOBERANIA, PODER E DIREITO EM REALE}

Para entendermos o modo pelo qual Reale pensa o Direito, é imprescindível que entendamos o que é, de fato, para ele o tridimensionalismo jurídico e a dialética de implicação e polaridade. Ele afirma que a teoria tridimensional do direito surge a partir da filosofia da cultura, que surge como espécie de aprimoramento da filosofia dos valores, a qual, por sua vez, critica os excessos do formalismo ético de matriz kantiana.

Segundo Reale, Kant separa no mundo fenomenal o "mundo da liberdade" (campo da ética) do "mundo da natureza" (campo da ciência) e afirma que somente se pode falar em experiência e, portanto, razão prática, no campo da ciência, isto é, no "mundo da natureza". Dessa forma, segue Reale, Kant exclui a ética e, assim, o direito de qualquer forma teorética de experiência (histórica, por exemplo), colocando-os no plano dos imperativos da vontade pura ${ }^{20}$.

17 FOUCAULT, Michel. Microfísica do poder. São Paulo: Graal, 2009. p. 179 e ss.

18 FOUCAULT, Michel. Op. cit., p. 182.

19 FERRAZ JUNIOR, Tércio Sampaio. Estudos de filosofia do direito. São Paulo: Atlas, 2009. p. 17.

20 REALE, Miguel. Teoria tridimensional do direito. São Paulo: Saraiva, p. 83 e ss. 
Percorrendo o itinerário que o fez chegar ao tridimensionalismo, Reale descobre em Radbruch e em Lask autores que perceberam que, não obstante o corte kantiano entre ser e dever-ser, havia também em Kant um conceito que os permitiria abordar e compreender o mundo histórico: o conceito de valor.

Segundo Radbruch ${ }^{21}$, na relação dual clássica de Kant entre sujeito e objeto, haverá sempre o elemento valor envolvido. Isso porque, no ato em que algo é conhecido, já se põe o valor daquilo que se conhece. O que se quer dizer é que o objeto torna-se objeto em função da intencionalidade da consciência e, nesta, na consciência, surge como objeto valioso. Dessa maneira, a própria filosofia dos valores trouxe a ideia de que entre realidade e valor haveria a cultura, que se caracterizaria por ser um complexo de realidades valiosas, como elemento de conexão.

Reale dirá, dessa forma, que todo bem de cultura (e o direito é um deles) é necessariamente tridimensional e só dessa forma pode ser enunciado: há um suporte natural ou real (Reale preferirá dizer ideal) que adquire significado e forma próprios, em razão de um valor de referência. Enuncia, assim, a tríade fato, valor e norma ${ }^{22}$.

Como afirma Reale, na relação cognoscente não é possível reduzir o sujeito ao objeto e vice-versa; e, sendo contínua tal relação, disso resulta o caráter dialético do conhecimento. Assim, para ele, o conhecimento permanece sempre aberto a novas possibilidades e é, pois, de natureza relacional. Os termos dessa relação são irredutíveis, vista a impossibilidade de redução do sujeito ao objeto ou o contrário, de forma que Reale, fazendo tais observações, chega à dialética de implicação-polaridade, a qual não permite síntese definitiva, em razão da irredutibilidade mesma de seus termos (opostos).

Nessa dialética de implicação-polaridade, afirma Reale:

Há uma correlação permanente e progressiva entre dois ou mais termos, os quais não se podem compreender separados um dos outros, sendo, ao mesmo tempo, irredutíveis uns aos outros; tais elementos distintos ou opostos da relação, por outro lado, só têm plenitude de significado na unidade concreta da relação que constituem, enquanto se correlacionam e dessa unidade participam. ${ }^{23}$

A cultura aqui é o processo das sínteses progressivas e infinitas que o espírito segue realizando com base no seu entendimento da natureza. Assim, como para Reale a experiência jurídica é uma das modalidades da experiência

21 RADBRUCH, Gustav. Filosofia do direito. São Paulo: Martins Fontes, 2004. p. 5 e ss.

22 REALE, Miguel. Teoria tridimensional do direito. Op. cit., p. 83 e ss.

23 REALE, Miguel. Teoria tridimensional do direito. Op. cit., p. 90. 
histórico-cultural, segue-se que está compreendida na implicação polar fato-valor, que se resolve em um processo normativo de natureza integrante.

Segundo Reale, as normas ou conjunto de normas correspondem, em dado momento histórico e sob circunstâncias específicas, à compreensão operacional da incidência de determinados valores a fatos diversos gerando, assim, a formação dos modelos jurídicos. A isso Reale denomina tridimensionalismo, ao qual se chega por um processo cognoscente de natureza dialética, tal como é a realidade: a dialética de implicação-polaridade.

Bem, se para Reale essas conclusões foram alcançadas com o suporte de uma filosofia da cultura, sendo a cultura um complexo de realidades valiosas, e observando que o processo de conhecimento e a própria realidade obedecem ao processo dialético descrito, não só o direito terá esta natureza tridimensional, mas também, por exemplo, a soberania. Por isso, Reale pode tratar o tema soberania desdobrando-a conforme os vértices de seu tridimensionalismo.

Tratando-a de um ponto de vista genético ou histórico-social, afirma que a soberania é o poder que possui uma sociedade historicamente integralizada como Nação de se constituir em Estado, pondo-se como pessoa jurídica; por outro lado, do ponto de vista técnico-jurídico, a soberania seria o poder de uma Nação já constituída juridicamente, sendo o poder do Estado na forma do ordenamento jurídico objetivo, que é o grau máximo de positividade; e, por fim, sob o foco ético-político, soberania seria o meio indispensável à realização do bem-comum em toda convivência nacional ${ }^{24}$.

Cumpre alertar, com Bodin, que a soberania é una e indivisível. Reale aduz que tríplice é apenas a forma de conhecê-la. Dito isto, tem-se que, no primeiro momento, referido exerce-se o poder no plano fático-histórico-social e funda-se o Estado; depois, com o Estado constituído, tem-se o poder institucionalizado: enquanto a Constituição está em vigor, o poder do Estado não é força arbitrária, mas institucionalizada ${ }^{25}$. Esse poder jurídico não é arbitrário, para Reale, nem mesmo quando exercido excepcionalmente, o que foi radicalizado por Schmitt, quando afirmou que o Soberano é aquele que decide sobre o Estado de Exceção ${ }^{26}$; por fim, a soberania encontra sua dimensão teleológica, de instrumento para se buscar o bem-comum (valor).

Conclui-se, portanto, que a relação da soberania com o Poder e o Direito dá-se, para Reale, também de forma tridimensional. A depender do momento e forma como se dá a interferência do Poder Soberano.

\footnotetext{
24 REALE, Miguel. Teoria do direito e do estado. São Paulo: Saraiva, 2003. p. 138 e ss.

25 HAURIOU, Maurice. Principios de derecho público y constitucional. Granada: Comares, 2003.

26 SCHMITT, Carl. Teologia política. Belo Horizonte: Del Rey, 2006. p. 7.
} 


\section{PLURALISMO JURÍDICO, DINÂMICA DA CORRELAÇ̃̃o PODER E DIREITO E GRADAÇÃO DA POSITIVIDADE}

Ao tratar de soberania popular e nacional, Reale afirma que o povo é uma construção, que o homem cívico, imaginado em dia das eleições, não existe. $\mathrm{E}$ reforça a ideia ao aduzir que o que há é o homem que trabalha: o agricultor, o comerciante, o operário etc. Havendo essa divisão funcional, Reale diz que a sociedade acaba por formar vários círculos de interesse e, neles, diversos grupos, associações, corporações, fatos, valores e normas também se relacionam ${ }^{27}$.

Segunda essa ideia, a sociedade vive e, dessa maneira, impede a estagnação do Direito. O cerne desse raciocínio nos conduz à conclusão, almejada por Reale, segundo a qual a institucionalização do Poder, que se dá de forma jurídica, gera apenas um equilíbrio instável, pois é sempre uma conjugação de estabilidade e movimento: a norma resultante da interação entre fatos e valores de hoje implica novos fatos e valores amanhã e pode até mesmo vir a constituir-se fato novo que servirá de suporte para normas futuras ${ }^{28}$.

O cerne do pluralismo de Reale está na afirmação de que a existência desses círculos sociais autônomos gera pressões fático-axiológico-normativas, visto que, no interior de cada um desses círculos, normas são produzidas e, para tanto, necessária é a existência do poder que atuaria como elemento catalisador dos fatores da tríade. Este processo é o que Reale chama de tridimensionalismo dinâmico e ele dá origem ao pluralismo jurídico e à gradação de positividade, duas outras noções relevantes do pensamento de Miguel Reale, conforme se expõe a seguir.

A interação progressiva e contínua dos fatores da tríade de uma forma geral, bem como, em particular, no interior dos diversos círculos sociais de poder, revela o pluralismo jurídico, isto é, ordens normativas parciais que regem relações no interior desses grupos e que tendem a pressionar a ordem jurídica total (expressão de Reale) para se positivarem em grau máximo.

Se, conforme se viu, para Reale não há como excluir do Direito o Poder ${ }^{29}$, sendo que este, o poder, atua, incide (relaciona-se) sobre os fatores da tríade também em esferas menos abrangentes, quer-se dizer, em diferentes círculos sociais, parece claro que para o nosso autor há poderes difusos na sociedade. Sendo assim, por óbvio, havendo ordens jurídicas parciais, há o que Reale denomina gradação de positividade.

27 REALE, Miguel. Obras políticas (1 ${ }^{\text {a }}$ Fase - 1931/1937). Brasília: Editora UnB, 1983. p. 78 e ss. e 171 e ss.

28 Anotações realizadas durante palestra proferida por Tércio Sampaio Ferraz Junior na Faculdade de Direito da USP (2010).

29 No mesmo sentido: BOBBIO, Norberto. Direito e poder. São Paulo: Unesp, 2008; LAFER, Celso. Hobbes visto por Bobbio. Revista Brasileira de Filosofia, v. XXXIX, fasc. 164, out./nov./dez. 1991. 
Essa formulação realeana é bastante interessante e complexa. Parte da filosofia da cultura, identificando o direito como objeto cultural, para construir sua teoria tridimensional do direito; depois, percebendo que a sociedade é multifária e diversificada, percebe que ela própria se subdivide em variados círculos de interesse, os quais produzem normas jurídicas que regem suas respectivas relações, constatando, portanto, a existência de um pluralismo jurídico concreto e efetivo; por fim, por decorrência afirma a gradação da positividade, visto que o pluralismo jurídico existente, no qual tanto de forma geral, quanto na particularidade da cada círculo de interesse, os fatores da tríade relacionam-se e sofrem a interferência do poder, terminando por revelar níveis distintos de positividade.

Com essas constatações, Reale afirma que não se pode conceber a ordem jurídica como ordem estática (Kelsen, em sua dinâmica ${ }^{30}$ ), ou como resultado definitivo de um processo de adaptação, o que significaria perder o sentido íntimo do Direito e confundir a ordem jurídica substancial (da sociedade complexa) com a ordem jurídica formal. Neste ponto, resta claro que Reale afasta-se de Kelsen, cuja dinâmica não vai além da produção de normas por órgãos competentes para tal, segundo normas preexistentes do ordenamento estatal e hierarquicamente organizadas.

A gradação de positividade de Reale refere-se, pois, à conexão e relação entre dois fenômenos só aparentemente contraditórios: de um lado, a progressiva autonomia de um número cada vez maior de círculos sociais em um país; e, de outro, a formação de um círculo social eminente (o ordenamento estatal), ao qual todos se referem e do qual todos recebem garantia ${ }^{31}$.

Como essa fragmentação proporcionada pelo pluralismo jurídico e pela noção de gradação de positividade pode vir a ser um fator de fragilização da ordem jurídica estatal, Lafer afirma que a Soberania dever ser o centro geométrico da positividade, como seu grau máximo, controlando os demais círculos, isto é, recebendo, ou não, como direito as normas provenientes das ordens jurídicas parciai $^{32}$. A positividade exige uma decisão e a positividade plena, ou máxima, uma decisão de última instância ${ }^{33}$.

\section{A INSTITUCIONALIZAÇÃO DO PODER. DESPERSONALIZAÇÃO E TRANSPERSONALIZAÇÃOO - A REDUÇÃOO DO QUANTUM DESPÓTICO}

Para que a relação entre esses círculos parciais e a ordem jurídica total seja harmônica, de forma a conciliar estabilidade e mobilidade sociais, faz-se

30 KELSEN, Hans. Teoria geral do direito e do estado. São Paulo: Martins Fontes, 2004.

31 REALE, Miguel. Pluralismo e liberdade. Rio de Janeiro: Expressão e Cultura, 1998. p. 231 e ss.

32 Anotações de palestra proferida na Faculdade de Direito da USP (2010).

33 Neste ponto, Reale parece aproximar-se da concepção de Schmitt, segundo a qual o poder se manifesta por meio de uma decisão, mesmo quando uma norma é aplicada. 
fundamental o processo de despersonalização do Poder. Essa despersonalização significa institucionalização do poder, de maneira que ele se apresente de modo menos opressor ou nu, permitindo a pluralidade jurídica da sociedade por meio da liberdade dos indivíduos.

Esse processo de despersonalização gera a redução do quantum despótico e favorece os processos de democratização do poder no Estado de Direito. A institucionalização do Poder faz com que o seu exercício decorra de imperativos legais e não de ordens subjetivas, ocorrendo, dessa forma, a jurisfação do Poder, sua despersonalização e, assim, abertura mais evidente aos interesses de grupo ${ }^{34}$.

Reale, no entanto, vai além da despersonalização e fala também em transpersonalização do poder. A relação histórica intrincada entre Poder e Direito é que proporciona que se passe da despersonalização à transpersonalização do Poder, esta sendo a associação do Poder a algumas ideias ou princípios que transcendem o poder dominante e geram maior coesão social e legitimação desse mesmo poder ${ }^{35}$.

Por isso, Reale conclui que o Poder tende a ser cada vez mais: (a) expressão de uma ideia de direito, que se manifesta em pequenos círculos sociais, no seio dos Estados nacionais e até mesmo no plano internacional; (b) objetivo, despersonalizado e transpessoal; (c) expressão da integração progressiva dos círculos sociais, com garantia de campos autônomos de atuação para indivíduos e grupos (o que se relaciona à ideia de liberdade no sentido negativo); (d) fundado no consentimento dos governados como expressão das liberdades que se compõem em unidade (o que se relaciona à ideia de liberdade no sentido positivo) $)^{36}$.

Pode-se concluir, portanto, que, para Reale, o poder está difundido na sociedade em geral e que tende a objetivar-se cada vez mais. Além disso, Reale afirma que há de ser garantido um campo livre para a atuação dos indivíduos e grupos e que o poder deve contar com o consentimento dos governados para angariar legitimidade. Esses dois últimos pontos demonstram que Reale percebeu a importância dos conceitos clássicos de liberdade, principalmente da correlação entre essas liberdades negativa e positiva para a análise do poder, da forma como ele se manifesta e de suas relações com o Direito em especial ${ }^{37}$.

34 REALE, Miguel. Pluralismo e liberdade. Op. cit., p. 234 e ss.

35 REALE, Miguel. Pluralismo e liberdade. Op. cit., p. 241-242.

36 REALE, Miguel. Pluralismo e liberdade. Op. cit., p. 242.

37 BERLIN, Isaiah. Dois conceitos de liberdade. In: Estudos sobre a humanidade: uma antologia de ensaios. São Paulo: Companhia das Letras, 2002. 


\section{CONCLUSÃO}

O texto procurou fixar as bases para que se possa dar início ao exame do pensamento de Reale acerca das correlações entre poder e direito. Procurou investigar o que Reale entende por poder, traçando uma breve evolução contextualizada. Dessa forma, viu-se que, para a teoria tridimensional, o poder parece atuar como um catalisador nas relações travadas na tríade fato-valor-norma. Por outro lado, em alguns momentos afirma a necessidade de uma decisão. Essa decisão seria a manifestação do poder que opta entre valores no sentido de objetivar um ou alguns deles em detrimento de outro ou outros valores.

Reale fez essa afirmação ao refutar a tese de Kelsen sobre a coincidência entre Direito e Estado, ou de que ambos seriam meras configurações normativas. Para Reale, há sempre o poder que decide em razão dos fins do ordenamento $^{38}$, sendo que este poder não é arbitrário, visto que está inserido em contexto institucional específico ${ }^{39}$, todavia jamais pode ser reduzido simplesmente a uma norma.

Dessa maneira, quer se entenda o poder como uma relação, quer se admita a interferência decisória do poder, especialmente no momento nomogenético, viu-se que a teoria tridimensional em sua modalidade dinâmica, acrescida da noção de dialética de implicação-polaridade e do pluralismo jurídico realeano, todas essas propostas fornecem subsídios relevantes para análises renovadas do fenômeno jurídico em suas múltiplas manifestações e comprovam a importância, profundidade e atualidade do pensamento de Reale.

\section{REFERÊNCIAS}

ARON, Raymond. As etapas do pensamento sociológico. São Paulo: Martins Fontes, 2002.

BERLIN, Isaiah. Dois conceitos de liberdade. In: Estudos sobre a humanidade: uma antologia de ensaios. São Paulo: Companhia das Letras, 2002.

BOBBIO, Norberto. Direito e poder. São Paulo: Unesp, 2008.

BODIN, Jean. Los seis libros de la República. 4. ed. Madrid: Editorial Tecnos, 2006.

BRANCO, Paulo Gustavo Gonet. Vale quanto pode: a força jurídica da Constituição como pressuposto elementar do constitucionalismo atual. Revista de Direito Público, Brasília: Editora Síntese/IDP, n. 14, out./dez. 2006.

FERRAZ JUNIOR, Tércio Sampaio. Estudos de filosofia do direito. São Paulo: Atlas, 2009.

38 REALE, Miguel. Variações sobre o poder. 2004. Disponível em:<http://www.miguelreale.com.br/artigos/ varpod.htm>. Acesso em: 25 jun. 2010.

39 REALE, Miguel. Fundamentos do direito. São Paulo: RT, 1998. p. 213 e ss. 
FERREIRA FILHO, Manoel Gonçalves. Do processo legislativo. 5. ed. rev., ampl. e atual. São Paulo: Saraiva, 2002.

FIORAVANTI, Maurizio. Constitución: da la antiguedad a nuestros días. Madrid: Trotta, 2001.

FOUCAULT, Michel. Microfísica do poder. São Paulo: Graal, 2009.

GALA, Pedro Bravo. Estúdio preliminar. In: BODIN, Jean. Los seis libros de la república. 4. ed. Madrid: Editorial Tecnos, 2006.

HAURIOU, Maurice. Principios de derecho público y constitucional. Granada:

Comares, 2003.

KELSEN, Hans. Teoria geral do direito e do estado. São Paulo: Martins Fontes, 2004.

LAFER, Celso. Hobbes visto por Bobbio. Revista Brasileira de Filosofia, v. XXXIX, fasc. 164, out./nov./dez. 1991.

LEAL, Roger Stiefelmann. O Efeito vinculante na jurisdição constitucional. São Paulo: Saraiva, 2006.

LOCKE, John. Dois tratados sobre o governo: Livro II: Segundo Tratado. 1. ed. 2. tir. São Paulo: Martins Fontes, 2001.

LOEWENSTEIN, Karl. Teoria de la Constitución. Barcelona: Ediciones Ariel, 1979.

MARX, Karl. A questão judaica. Disponível em: <http://www.lusosofia.net/textos/marx questao_judaica.pdf>. Acesso em: 24 jun. 2010.

MONTESQUIEU. O espírito das leis. 3. ed. São Paulo: Martins Fontes, 2005.

RADBRUCH, Gustav. Filosofia do direito. São Paulo: Martins Fontes, 2004.

REALE, Miguel. Fundamentos do direito. São Paulo: RT, 1998.

. Pluralismo e liberdade. Rio de Janeiro: Expressão e Cultura, 1998.

- Teoria do direito e do estado. São Paulo: Saraiva, 2003.

. Teoria tridimensional do direito. São Paulo: Saraiva.

. Obras políticas (1aㅡ Fase - 1931/1937). Brasília: Editora UnB, 1983.

. Variações sobre o poder. 2004. Disponível em: <http://www.miguelreale.com.

br/artigos/varpod.htm>. Acesso em: 25 jun. 2010.

SCHMITT, Carl. Teologia política. Belo Horizonte: Del Rey, 2006.

SOUZA JÚNIOR, Cezar Saldanha. O tribunal constitucional como poder: uma nova teoria da divisão dos poderes. São Paulo: Memória Jurídica, 2002. 